\title{
The Relationship between Authentic Leadership and Employees' Virtual Loafing and Cynic Behaviors
}

\author{
Halil Özcan ÖZDEMIR \\ Ahi Evran Üniversity \\ Social Science Vocational School \\ Kırşehir, Turkey \\ orcid.org/0000-0002-0021-3618 \\ hoozdemir@ahievran.edu.tr
}

\author{
Hakan Vahit ERKUTLU \\ Nevşehir Hacı Bektaş Veli University \\ Faculty of Economics and Administrative \\ Sciences, Nevşehir, Turkey \\ orcid.org/0000-0003-2441-3603 \\ erkutlu@,nevsehir.edu.tr
}

\begin{abstract}
The main purpose of this study is to investigate whether the managers' authentic leadership styles affect employees' organizational cynicism and virtual loafing behavior. The sample of the study consists of 208 administrative staff at Ahi Evran University. According to the results of the study, it is clear that the authentic leadership reduces organizational cynicism and does not reduce the virtual loafing; and organizational cynicism behaviors have an increasing effect on virtual loafing. Sample of the research consists of administrative personnel working at Ahi Evran University located in Kırşehir. First of all, descriptive statistics, correlation, and hierarchical regression analyses were conducted related to the hypotheses tests. The results of these analyses revealed that a negative relationship existed between authentic leadership and organizational cynism, while there was a positive relationship between organizational cynism and virtual loafing. Moreover, no negative relation was found between authentic leadership and virtual loafing, which was one of the hypotheses of the research.
\end{abstract}

Keywords: Authentic leadership, organizational cynicism, virtual Loafing

\section{1- Introduction}

Factors of the human resources such as knowledge, experience, attitude and behavior which are among the most important resources in organizational terms play an important role in achieving the aims of organizations. It is also related to the leadership styles of the managers who have sufficient knowledge and skills in the subject they serve, their virtual loafing and their lack of cynicism towards their organization.

The main objective of the study is to determine whether managers of administrative staff working at public institutions are affected by authentic leadership behaviors; and to determine the level of the influence of managers' cynicism and virtual loafing behavior on authentic leadership behaviors. Another aim of the research is to determine whether managers differ in their authentic leadership behaviors according to their gender, age, education, marital status, and seniority; and whether there is a 
difference between cynical behavior and virtual loafing behaviors of the public personnel.

In addition to the authentic leadership behaviors of the administrators in public institutions; it is also of great importance that employees are likely to have an adverse effect on corporate productivity and that their impact on cynicism and virtual loafing behavior is determined and guided by relevant managers. Furthermore, empirical studies that measure the relationship between authentic leadership, organizational cynicism and virtual loafing behaviors which have not been done before is of great importance in terms of leading the researchers who will work on it.

Data collection and interpretation, which is a field research, was used in this study. In the scope of the research, literature review was performed first. Then; the results were obtained using authentic leadership, organizational cynicism and virtual loafing scales, and some data were analyzed with the help of the SPSS program. The results of the analyzes were compared with the literature results to reach the final state of the research.

\section{2- Literature Review and Hypotheses}

\subsection{Authentic leadership and organizational cynicism}

Looking at the work of the relationship between authentic leadership and organizational cynicism, it has been seen that there are works of Laschinger et al. (2013) and Polatcan and Titrek (2014) on this field. In their research on the health sector, Laschinger and others (2013) reached the conclusion that authentic leadership behaviors of head nurse, working conditions of nurses, and empowerment perceptions affect nurses' emotional exhaustion and cynicism. Tabak et al. (2013) examined in their works on authentic leadership perceptions of employees of a Turkish company in relation to organizational trust, organizational commitment, and organizational cynicism. As a result of that study; they came to conclusion that authentic leadership has a positive relation with organizational trust and organizational commitment; and it has a significant negative relationship with organizational cynicism. In the Polatcan and Titrek (2014)'s surveys, they aimed to determine the relationship between authentic leadership behaviors of school principals and organizational cynicism of teachers. As a result of the research, Polatcan and Titrek (2014) found a moderate and negative relationship between the authentic leadership behaviors and cynicism. Tabak et al. (2013) examined about the authentic leadership perceptions of the employees of a Turkish company in relation to organizational trust, organizational commitment, and organizational cynicism in their works. According to this study; they came to conclusion that authentic leadership has a positive relation with organizational trust and organizational commitment; and it has a significant negative relationship with organizational cynicism.

Authentic leaders; those who are known and respected for their honesty, who are aware of who they are and who know what they believe, who value transparency and consistency in their judgments, ethical reasoning and attitudes, and who focus on developing a positive mood among themselves and with their colleagues in trust, optimism and flexibility (Avolio et al.,2007). Within the scope of this research, organizational cynicism has been considered as a negative attitude towards the employee. When both the above research findings and the definitions and components of authentic leadership in organizational behavior literature are evaluated, it is assumed that authentic leaders may have an organizational cynicism-reducing effect, which is 
one of the negative attitudes towards organization. We can develop the first hypothesis of our research from that point.

$\mathrm{H}_{1}$ : There is a negative relationship between authentic leadership and organizational cynicism.

\subsection{Authentic leadership and virtual loafing}

Relational studies between authentic leadership and virtual loafing have not been studied much in the literature; Lee, Chen and Liou (2015) have done the closest work on this subject. Our work is a pioneering work in this sense. Lee, Chen and Liou (2015) found in their work that in the perceived social loafing, the lead of taxpayers indirectly has a negative influence on tax collectors. Mentioned researchers investigated the relationship between leadership and social loafing rather than authentic leadership and virtual loafing. Within the scope of this research, virtual loafing was evaluated from the point of personal use of the computers and smart phones, not for the business purposes, while the employee is at the workplace. When these limited studies in the literature are evaluated, it is assumed that authentic leaders can have a negative effect on virtual rescue behaviors. We can develop the second hypothesis of our research.

Murphy and others (2003) found that in their studies; individual social change associations that are shaped at the workplace play a role in mediating the relationship between social loafing, distributed justice, and perceptions of interaction. In particular, there may be a mediating relationship between leading member exchanges and team member exchanges, social loafing and intervening justice. In addition, leading member exchanges may have an intermediary relationship between justice distribution and social loafing behavior. When the research results of the researchers are examined; it is seen that there is a significant relationship between the interaction of justice and leader members; and the interaction of justice and team members. There is a negative relationship between leader member Exchange and social loafing, but there is no of it in team member change. It appears that the distribution of justice does not have a significant relationship with the leading member exchange. This does not support the fact that there is a change of leader member as an intermediary role between the distributed justice and social loafing (Murphy et al.,2003)

$\mathrm{H}_{2}$ : There is a negative relationship between authentic leadership and virtual loafing.

\subsection{Organizational cynicism and virtual loafing}

The behavior of organizational cynicism increases the virtual loafing behavior. In the literature, it was found that there are studies that measure the relationship between organizational cynicism and burnout or perverse behavior rather than the relationship between organizational and virtual loafing. The study that is closest to our research on the subject is the work done by Shahzad and Mahmood (2012). Cynicism is a thought that belongs to people who are constantly critical of the events and who are full of fond and negative thoughts. The basis of the concept of cynicism is that people leave positive personality characteristics such as honesty and justice for their personal interests to the second plan. Cynicism can be arised from an individual's own personality traits or from their own organization's traits (Eaton 2000). According to the results of these studies, researchers found a meaningful and positive relationship between organizational cynicism and deviant behavior in the organization. When these limited studies in the literature are evaluated, it is assumed that organizational cynicism might increase the virtual recording. We can develop the third hypothesis of our research from that point of view as: 
$\mathrm{H}_{3}$ : There is a positive relationship between organizational cynicism and virtual loafing.

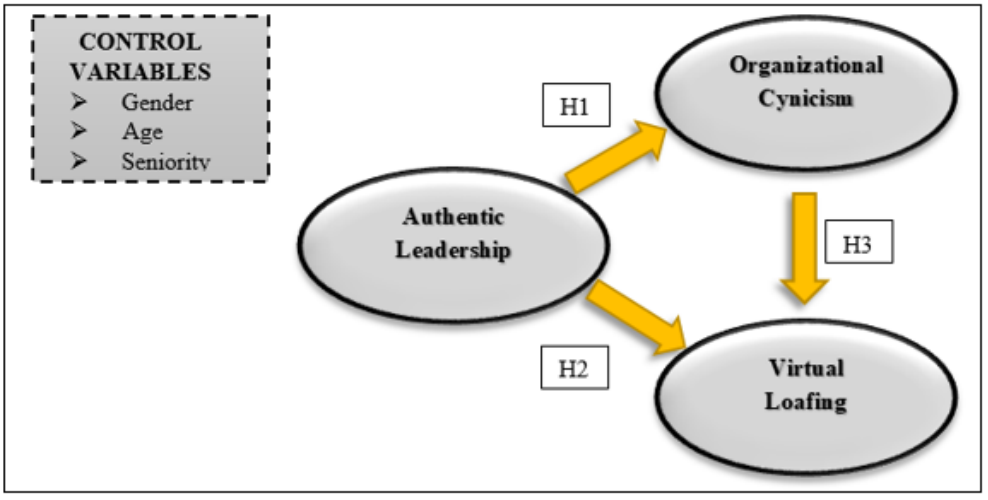

\section{3- Methods}

Figure 1 Theoretical model of study

The sample of this study is formed with 208 administrative staff at Ahi Evran University. While measuring the authentic leadership behaviors of managers in the research; an authentic leadership scale of 16 items developed by Avolio, Gardner and Walumbwa (2007) was used. The sample materials in the questionnaire are in the form of 'My manager tells clearly what he wants to say' and 'My manager takes decisions based on his own values'. The answers to the questionnaire range from 1 (I do not agree) to 5 (I strongly agree). The reliability coefficient of the questionnaire is 0.94 .

While measuring the behavior of cynicism of employees; an organizational cynicism scale consisting of 13 items developed by Brandes, Dharwadkar and Dean (1999) was used. The sample materials in the questionnaire are in the form of 'I believe that what is said and what is done are different in the institution' and 'I am annoyed when I think of the institution I work with'. The answers to the questionnaire range from 1 (I do not agree) to 5 (I strongly agree). The reliability coefficient of the questionnaire is 0.92 .

Finally, a virtual loafing scale consisting of 22 items developed by Blanchard and Henle (2008) was used to measure the employees' virtual loafing behaviors. Measurements were performed with a scale of 5 likert type; $(1=$ strongly disagree, $5=$ strongly agree) the examples may be given from the items such as 'I play online games' and 'I download music from the internet'. The reliability coefficient of the questionnaire is 0,89 .

Within the scope of the survey, 210 administrative staff members replied as answered from 220 questionnaires distributed in total. Because of the unhealthy and incomplete data of the 2 replied questionnaires, these 2 questionnaires were excluded from the study. Within the scope of the research, 208 questionnaires were used to obtain the results. In this context, the approximate rate of return was $95 \%$.

\section{4- Validity and reliability analysis}

The authentic leadership scale with 16 items, the organizational cynic scale with 13 items, and the virtual loafing scale with 22 items used in this thesis study were tested by factor analysis and reliability techniques for structural validity. Despite the fact that there are 16 items on the authentic scale related to authentic leadership, Factors 5, 6 and 9 were subtracted from factor analyzes and the scale was reduced to 13 items. There are 22 items on the original scale of the virtual loafing, and because 5 of these items show 
internet and e-mail standards of employers and employees (Items 11, 12, 14, 15, 19); Items 4, 6, 8, 10 and 22 were omitted for the purpose of reflecting the variance of the original values as a result of the factor analysis. Thus, in this study, 12 items were used which are appropriate to the subject related to virtual loafing. As a result of the new scale reduction in factor analysis, coefficients of Cronbach Alfa have also changed. These changes have occurred in the revised authentic leadership and the revised virtual loafing (Özdemir, 2017a).

According to this; the total Cronbach Alpha coefficient was found to be 0.926 in the new reliability test for the collected data with the authentic leadership questionnaire $(p<0,001)$. The Cronbach Alpha coefficient was found to be $0.790(\mathrm{p}<0.001)$ in the new reliability test which is related to virtual loafing. Factor analysis with organizational cynicism scale showed that the scale had the same effect as the original scale. Therefore, the Cronbach Alpha coefficient was found to be 0.915 as previously calculated $(\mathrm{p}<0.001)$. The newly found Cronbach Alpha values also show that the scales are reliable (Özdemir, 2017a).

\section{5- Results}

Table 1. Socio-demographic characteristics of survey participants $(\mathbf{N}=\mathbf{2 0 8})$

\begin{tabular}{|c|c|c|c|}
\hline VARIABLES & בATEGORY & $\overline{\mathbf{f f}}$ & 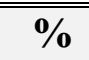 \\
\hline \multirow[t]{2}{*}{ Gender } & Male & 142 & 688,3 \\
\hline & Female & 66 & 31,7 \\
\hline \multirow[t]{2}{*}{ Marital Status } & Married & 163 & 78,4 \\
\hline & Single & 45 & 21,6 \\
\hline \multirow[t]{5}{*}{ Training Level } & Primary education & 5 & 2,4 \\
\hline & High school & 34 & 16,3 \\
\hline & Two-year degree & 42 & 20,3 \\
\hline & Bachelor's degree & 118 & 56,7 \\
\hline & Post graduate & 9 & 4,3 \\
\hline \multirow[t]{5}{*}{ Age Group } & 20 and below & 2 & 1,2 \\
\hline & Between 21-30 & 64 & 30,8 \\
\hline & Between 31-40 & 90 & 43,0 \\
\hline & Between 41-50 & 32 & 15,4 \\
\hline & 51 and above & 20 & 9,6 \\
\hline \multirow[t]{7}{*}{ Seniority (month) } & 12 and below & 14 & 6,7 \\
\hline & Between 13-60 & 108 & 51,9 \\
\hline & Between 61-120 & 36 & 17,3 \\
\hline & Between 121-180 & 10 & 4,8 \\
\hline & Between 181-240 & 11 & 5,3 \\
\hline & Between 241-300 & 16 & 7,7 \\
\hline & 301 and above & 13 & 6,3 \\
\hline
\end{tabular}


When the distribution of employees according to gender is examined in Table 1, $68.3 \%$ of the employees were male $(n=142)$ and $31.7 \%$ were female $(n=66)$. When the marital status of the employees whose opinions are taken within the scope of the research is examined; $78.4 \%$ were married $(n=163)$ and $21.6 \%$ were single $(n=45)$. When the educational status of the administrative staff participating in the survey is examined; $(\mathrm{N}=5), 16,3 \%$ were high school $(\mathrm{n}=34), 20,3 \%$ were associate degree $(\mathrm{n}$ $=42), 56,7 \%$ were licensed $(n=118)$, and $4,3 \%$ were graduates of graduate school $(n$ $=9)$. When the age groups of the administrative personnel in the scope of the research are examined; $(n=2), 30.8 \%$ of the patients were between the ages of $21-30(n=64)$, $43 \%$ were between the ages of $31-40$ years $(n=90), 15 \%(N=32)$, and $9.6 \%$ were older than 51 years $(n=20)$. The Pearson Correlation coefficients of the variables in the study are given in Table 2 .

Table 2. Average of variables, standard deviation, correlation coefficients

\begin{tabular}{|c|c|c|c|c|c|c|c|c|c|}
\hline Variables & Mean & S.d & 1 & 2 & 3 & 4 & 5 & 6 & 7 \\
\hline 1.Gender & 1,32 & 0,47 & & & & & & & \\
\hline 2.Marital Status & 1,22 & 0,41 & 0,07 & & & & & & \\
\hline 3.Educational Level & 3,44 & 0,90 & $0,15^{*}$ & 0,12 & & & & & \\
\hline 4.Age & 36,47 & 8,68 & $-0,21^{* *}$ & $-0,34^{* *}$ & $-0,33^{* *}$ & & & & \\
\hline 5.Seniority (month) & 99,92 & 96,72 & $-0,09$ & $-0,26^{* *}$ & $-0,30^{* *}$ & $0,70^{* *}$ & & & \\
\hline 6.Authentic Leadership & 3,45 & 0,87 & 0,00 & 0,09 & 0,08 & $-0,25^{* *}$ & $-0,20^{* *}$ & & \\
\hline 7.Cyberloafing & 2,23 & 0,65 & $-0,09$ & 0,08 & $-0,03$ & $-0,02$ & 0,02 & 0,09 & \\
\hline 8.Cynicism & 2,48 & 0,88 & 0,06 & $-0,04$ & 0,04 & 0,07 & 0,12 & $-0,26^{* *}$ & $0,37^{* *}$ \\
\hline
\end{tabular}

When the information in Table 2 is examined, there is a positive low level relationship ( $r=0,37, p<0,01)$ between organizational cynicism and virtual loafing; and there is a negative low level relationship $(r=-0,26, p<0,01)$ between authentic leadership and organizational cynicism. It is determined that there is a negative low level of relationship $(r=-0,20, p<0,01)$ between authentic leadership and administrative staff years (seniority) in the institution; and there is also a negative low level of relationship $(r=-0,25, p<0,01)$ related to the age of employees with authentic leadership. There is a high positive relationship $(r=0,70, p<0,01)$ between the years of employment (seniority) and the ages of employees. It is determined that there is a low level of relationship $(\mathrm{r}=-0,30, p<0,01)$ between seniority and education level of employees; and also there is a negative low level of relationship $(r=$ $0,26, p<0,01)$ between the seniority and marital status of the employees. It is determined that there was a negative low level relationship between the ages of the employees and the education levels $(r=-0,33, p<0,01)$, and a negative low level relationship between the ages of the employees and the marital status $(r=-0,34, p<0$, 01 ), and a negative low relationship between the ages of the employees and the gender $(r=-0,21, p<0,01)$. In addition, there was a positive relationship between education levels of employees and gender $(r=0,15, p<0,05)$. 
Table 3. Hierarchical regression analysis results for organizational cycnicism ${ }^{a}$

\begin{tabular}{lcc}
\hline VARIABLES & Model-1 & Model-2 \\
\hline Gender & 0,072 & 0,059 \\
\hline Age & 0,002 & $-0,057$ \\
\hline Seniority & 0,123 & 0,114 \\
\hline Authentic Leadership & & $-0,255^{* * *}$ \\
\hline$R^{2}$ & 0,019 & 0,080 \\
\hline Adjusted $R^{2}$ & 0,005 & 0,062 \\
\hline$F$ & 1,323 & $4,407^{* *}$ \\
\hline Change in $R^{2}$ & 0,019 & 0,061 \\
\hline${ }^{*} p<0.05 ;{ }^{* *} p<0.01 ;{ }^{* * *} p<0.001$ & & \\
\hline
\end{tabular}

$\mathbf{a}=$ Independent variable: authentic leadership

In Table 3, a hierarchical regression analysis was conducted to examine the behavior of organizational cynicism among administrative staff at Ahi Evran University, a public institution, and how much the authentic leadership behaviors of the managers are determined. If it is known that the independent variables have any effects on the dependent variable, it is appropriate to use the hierarchical regression analysis (Gürbüz and Şahin, 2016).

Hierarchical regression analysis results are statistically significant $[F=4,407 ; p<$ $0,01]$. When the data in Table 3 are examined, the $\mathrm{R}^{2}$ value is 0,080 . This result shows how much of the change in the dependent variable (organizational cynicism) is explained by the independent variable (authentic leadership). According to this, it can be said that the $8 \%$ change in organizational cynicism depends on authentic leadership. When you look at Beta coefficients; it can bee seen that when authentic leadership increases by 1 unit, organizational cynicism decreases by about 0 .

Table 4. Results of hierarchical regression analysis for virtual loafing ${ }^{b}$

\begin{tabular}{lcc}
\hline VARIABLES & Model-1 & Model-2 \\
\hline Gender & $-0,096$ & $-0,092$ \\
\hline Age & $-0,083$ & $-0,064$ \\
\hline Seniority & 0,066 & 0,069 \\
\hline Authentic Leadership & & 0,084 \\
\hline$R^{2}$ & 0,011 & 0,017 \\
\hline Adjusted $R^{2}$ & $-0,004$ & $-0,002$ \\
\hline$F$ & 0,733 & 0,890 \\
\hline Change in $R^{2}$ & 0,011 & 0,007 \\
\hline$p<0.05 ;{ }^{* * *} p<0.01 ;{ }^{* * *} p<0.001$ & & \\
\hline
\end{tabular}

$\boldsymbol{b}=$ Independent variable: authentic leadership 
In table 4, a hierarchical regression analysis was conducted to examine the extent to which the virtual rescue behaviors of administrative staff at Ahi Evran University stem from authentic leadership behaviors. Hierarchical regression analysis results are not statistically significant $[F=0,890 ; \mathrm{p}>0,005]$. When the data in Table 4 are examined, the $\mathrm{R}^{2}$ value is 0,017 . This result shows how much of the change in the dependent variable (Virtual Loafing) is explained by the independent variable (authentic leadership). According to this, it can be said that the change of about $2 \%$ in the virtual loafing depends on authentic leadership. This is a very small amount.

Table 5. Results of hierarchical regression analysis for virtual loafing ${ }^{c}$

\begin{tabular}{lcc}
\hline VARIABLES & Model-1 & Model-2 \\
\hline Gender & $-0,096$ & $-0,124$ \\
\hline Age & $-0,083$ & $-0,084$ \\
\hline Seniority & 0,066 & 0,019 \\
\hline Organizational Cynicism & & $0,383^{* * *}$ \\
\hline$R^{2}$ & 0,011 & 0,154 \\
\hline Adjusted $R^{2}$ & $-0,004$ & 0,138 \\
\hline$F$ & 0,733 & $9,270^{* * *}$ \\
\hline Change in $R^{2}$ & 0,011 & 0,144 \\
\hline
\end{tabular}

${ }^{*} p<0.05 ;{ }^{* *} p<0.01 ;{ }^{* * *} p<0.001$

$\boldsymbol{c}=$ Independent variable: organizational cynicism

In table 5, a hierarchical regression analysis was conducted to examine the extent to which the participant's virtual loafing behaviors originated from organizational cynicism behaviors. Hierarchical regression analysis results are statistically significant $[F=9,270 ; p<0,001]$. When the data in Table 5 are examined, the $\mathrm{R}^{2}$ value is 0,154 . This result shows how much of the change in the dependent variable (virtual loafing) is explained by the independent variable (organizational cynicism). According to this, it can be said that about $15 \%$ change in the virtual loafing depends on organizational cynicism. When you look at beta coefficients; when organizational cynicism increases by 1 unit, virtual loafing increases by about 0.38 units $(p<0,001)$ (Özdemir, 2017b).

\section{6- Conclusion and Evaluation}

As a result of the analyses made, the following results were obtained regarding the hypothesis tests. There is a negative relationship between authentic leadership and organizational cynicism. This case supports the works of Laschinger et al. (2013); Tabak et al. (2013); Polatcan and Titrek (2014) from the literature. There is no negative relationship between authentic leadership and virtual loafing. This case supports the works of Lee et al. (2015) and Murphy et al. (2003) in the literature. There is a positive relationship between organizational cynicism and virtual loafing. This case supports the works of Aghaz and Sheikh (2016); Shahzad and Mahmood (2012); Gün and Turunc (2015).

The results obtained in the study also suggest some suggestions for implementation: (1) for the result that the authentic leadership did not reduce the virtual loafing; it can be said that the virtual loafing might be caused by the organizational culture, the personality characteristics of the occupation, the organizational structure, and the nature of the task performed. Therefore, the organization's culture and work to 
be done to improve the quality of the work done; it can be assessed that the occupants can have an effect in reducing the virtual loafing behavior. (2) When it is thought that the behavior of organizational cynicism increases the virtual loafing, employee need to work to understand and reduce cynical behavior. Reduced cynicism behavior will also reduce virtual loafing behaviors, so that the employee will not have wasted time. The efficiency, productivity, and profitability will be increased when the time to waste is used for the workplace. In this context, managers should try to find out the reasons underlying the behavior of cynicism and to make efforts to improve it. It is also important to provide training to resolve cynicism and virtual loafing behaviors. (3) For businesses, the reduction of cynicism behavior and virtual rescue behaviors of staff will bring increased efficiency and performance. Hence, it can be said that it is beneficial for managers to have leadership related to authentic leadership and effective management, development of managerial skills and advanced management skills. (4) Taking into account variables such as organizational culture, personality traits of employees, organizational structure, and the nature of the task being undertaken will help to get better results. (5) Organizational cynicism and virtual loafing can also be caused when the organizational structure is very over-hierarchical. This can create some strain on employees. Some social activities can be organized to reduce the tension, such as picnic arrangements and weekend activities. Since the hierarchical organization structure is more disciplined and controllable, virtual loafing out behaviors may be less. In the flexible organizational culture, more virtual loafing can be seen because it is a family or friendly environment. The existence of an organizational culture that will balance these two situations is more important for the reduction of virtual loafing behaviours. These are; it can lead to a decrease in the virtual loafing due to cynicism. (6) Organizational culture can be amendable by opening an ethical organizational culture, recruitment training for new employees, and periodic trainings for current employees. Job descriptions of each employee are clearly defined. In this respect, the responsibilities and authorities of the employees can be determined. An ethical organizational culture can lead employees not to focus on their work merely in a social and virtual sense of activity. (7) Also the quality of the task being performed is an important issue. The task may be or may not be a routine. Routine tasks may cause monotony. Hence, employees may move to loafing behaviors in order to break their monotony. In order to prevent employees from saving the virtual loafing sense, managers need to save the work done from monotony. The application of rotation in this regard may be an effective method of recovering from monotony.

There are also some limitations to this work. Factors such as the organizational structure that originated from the the place where the research is done being the public institution may have affected the findings. For this reason, doing the same work in private sector may bring different results. Secondly, demographic factors may have affected the outcomes. Most of the participants in the survey consisted of men $(\% 68,3)$ and employees with a term of less than 5 years $(\% 51,9)$. If future work is to be applied to a different gender composition and more senior employees, different outcomes may be achieved. In addition, those who participated in the survey may not reflect their true opinion in order not to give a negative impression to the managers or fear that the results of the survey might be explained. The fourth and final limitation of the study is; there might be some common variance bias in the study. According to Gürbüz and Sahin (2016), common method bias can also be called as the common method variance. The common method bias is the systematic error of variance between measured 
variables. Generally speaking, common method bias results from the collection of data on dependent and independent variables from the same source or from the same evaluator. Looking at the findings of this study, we believe that the following suggestions will be useful for those who will work on this field and for sector employees.

This study is a cross-sectional study conducted on the basis of the information given by the subjects at the moment. When organizational cynicism and virtual loafing are thought to have changed over time; making a spatial work on the topic may lead to more useful information being obtained.

"Important Note" This study is derived from the dissertation of Halil Özcan ÖZDEMIR and his presentation in the 25th Congress of National Management and Organization.

\section{References}

Aghaz A, Sheikh A (2016) Cyberloafing and job burnout: An investigation in the knowledge-intensive sector. Computers in Human Behavior, 62, 51-60.

Avolio BJ, Gardner WL, Walumbwa FO (2007) Authentic Leadership Questionnaire. www.mindgarden.com (29 Mart 2016).

Blanchard AL, Henle CA (2008) Correlates of different forms of cyberloafing: The role of norms and external locus of control. Computers in Human Behavior, 24(3), 1067-1084.

Brandes P, Dharwadkar R, Dean JW (1999) Does organizational cynicism matter? Employee and supervisor perspectives on work outcomes. In Eastern Academy of Management Proceedings, 150-153.

Eaton JA (2000) A social motivation approach to organizational cynicism. Doctoral Dissertation, Graduate Programme in Psychology, York University, Toronto.

Gün F (2015) Öğretim Elemanlarının Algılarına Göre Örgütsel Sinizm İle Tükenmişlik Düzeyleri Arasındaki İlişkinin İncelenmesi. Yüksek Lisans Tezi, Hacettepe Üniversitesi, Eğitim Bilimleri Enstitüsü, Eğitim Bilimleri Anabilim Dalı, Ankara.

Gürbüz S, Şahin F (2016) Sosyal Bilimlerde Araştırma Yöntemleri (Seçkin Yayıncılık, Ankara).

Laschinger HKS, Wong CA, Grau AL (2013) Authentic leadership, empowerment and burnout: a comparison in new graduates and experienced nurses. Journal of Nursing Management, 21(3), 541-552.

Lee PC, Chen CM, Liou KT (2015) Using Citizens' Leadership Behaviors to Enhance Worker Motivation: Reducing Perceived Social Loafing in a Coproductive Tax Service Program. Public Performance \& Management Review, 39(1), 172-197.

Murphy SM, Wayne SJ, Liden RC, Erdogan B (2003) Understanding social loafing: The role of justice perceptions and exchange relationships. Human Relations, 56(1), 61-84.

Özdemir HÖ (2017a) Yöneticilerin Otantik Liderlik Tarzlarının Calışanların Sanal Kaytarma ve Sinizm Davranşları Üzerine Etkileri. Doktora Tezi, Nevşehir Hacı 
Bektaş Veli Üniversitesi, Sosyal Bilimler Enstitüsü, İşletme Anabilim Dalı, Nevşehir.

Özdemir HÖ (2017b) Yöneticilerin Otantik Liderlik Tarzlarının Calışanların Sanal Kaytarma ve Sinizm Davranşları Üzerine Etkileri, 25. Ulusal Yönetim ve Organizasyon Kongresi Bildiri Kitabı Ankara, 25-27 Mayıs.

Polatcan M, Titrek O (2014) The relationship between leadership behaviors of school principals and their organizational cynicism attitudes. Procedia-Social and Behavioral Sciences, 141, 1291-1303.

Shahzad A, Mahmood Z (2012) The mediating-moderating model of organizational cynicism and workplace deviant behavior: (Evidence from banking sector in Pakistan). Middle-East Journal of Scientific Research, 12(5), 580-588.

Tabak A, Polat M, Cosar S, Türköz T (2013) A research on the consequences of authentic leadership. Bogazici Journal of Economics and Administrative Sciences, 27(2), 65-88.

Turunç Ö (2015) İş stresi-kaytarma ilişkisinde liderin rolü: turizm sektöründe bir araştırma. Uluslararası İktisadi ve İdari Bilimler Dergisi, 1(2), 142-159. 